\title{
SELF-HEATING EFFECTS ON STRAIN MEASUREMENTS PERFORMED BY EMBEDDED FIBRE OPTIC SENSORS UNDER CYCLIC LOADING
}

\author{
Leonardo D'Acquisto a and Roberto Montanini ${ }^{\mathrm{b}}$,* \\ ${ }^{a}$ Dipartimento di Meccanica , Università di Palermo, viale delle Scienze, 90128, Palermo, ITALY, \\ dacquisto@dima.unipa.it,, \\ ${ }^{b}$ DCIIM, Università di Messina, Salita Sperone, 131, 98166, Sant’Agata (ME), ITALY, \\ rmontanini@ingegneria.unime.it,
}

Keywords: infrared thermography, fibre Bragg gratings, composite materials

\section{State of the art}

Fibre Bragg Gratings are nowadays more and more used for strain measurements in several applications for structural health monitoring. The mechanical strain variation, which is transmitted from the structure under investigation to the fiber sensor, induces a Bragg wavelength shift which represents the measured quantity. This Bragg wavelength shift depends not only on the strain level applied to the FBG sensor, but also on the temperature because of the temperature dependent change in the refraction index (thermo optic coefficient $\xi$ ). The total Bragg wavelength shift is therefore the sum of at least two terms, namely the $\Delta \lambda_{\mathrm{B}, \mathrm{S}}$ (strain induced wavelength shift) and $\Delta \lambda_{\mathrm{B}, \mathrm{T}}$ (temperature induced wavelength shift).

$$
\begin{aligned}
& \Delta \lambda_{B S}=\lambda_{B} \cdot\left(1-p^{e f f}\right) \cdot \varepsilon \\
& \Delta \lambda_{B T}=\lambda_{B} \cdot(1+\xi) \cdot \Delta T
\end{aligned}
$$

where $\lambda_{\mathrm{B}}$ is Bragg wavelength of the FBG, $p^{\text {eff }}$ is photo-elastic coefficient of the optical fiber and $\Delta \mathrm{T}$ is the temperature change experienced by the FBG.

Due to their very low intrusivity, FBG sensors can be embedded into composite materials, providing real-time monitoring of the structural component under working conditions. Furthermore, embedded FBG sensors can be used to predict fatigue failures of structures subjected to cyclic loads.

Commercial interrogation systems provide a static thermal compensation by the use of a reference free-strain Bragg grating which experiences only the $\Delta \lambda_{\mathrm{B}, \mathrm{T}}$ induced by ambient temperature at the site of the interrogation system. Structural components instrumented with embedded FBG sensors can often experience temperature levels different from the temperature level to which the reference FBG is exposed. It can happen if they are exposed to thermal radiation from the surrounding environment or if they undergo a self heating due to cyclic loading. This latter condition has to be carefully taken into account especially for composite materials that in certain conditions (depending on the applied load and on the cycling frequency) can experience temperature variations up to some tens of degree. 
http://dx.doi.org/10.21611/qirt.2006.053

\section{Aim of the work}

The strain measurement error of embedded FBG sensors due to self heating will be investigated on specimens subjected to uniaxial tensile fatigue loads. Due to the dual sensitivity of Bragg grating sensors, this measurement error can be quite large, leading to unreliable evaluation of the actual stress level within the component. This aspect, which in Author's knowledge has never been deeply investigated in literature, is difficult to be managed by traditional thermal compensation techniques, because it strongly depends on the local temperature distribution within the specimen.

\section{Proposed approach}

To evaluate the strain measurement error due to self-heating of composite laminates in which a Bragg grating sensor has been embedded, experimental tests will be performed on differently shaped specimens by measuring the surface temperature distribution induced by cyclic loads with an infrared camera and by comparing it with the internal temperature distribution measured by means of either annealed distributed optical fibres thermometers or thermocouples (Fig.1). Cycling loads will be applied by an electro hydraulic testing machine. Experimental results will then be compared with a numerical model in order to predict the observed thermal flow within the specimen under specific testing conditions.

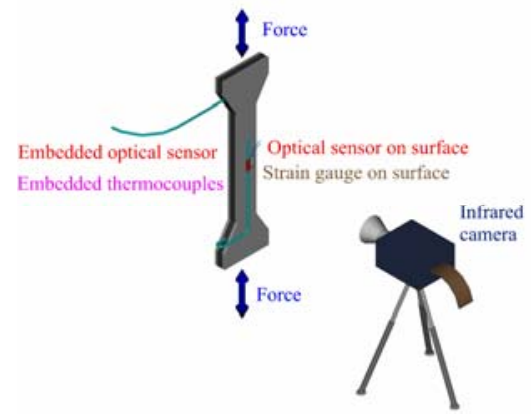

Figure 1 - Experimental setup

\section{References}

[1] Y.J. Rao, "Recent progress in applications of in-fibre Bragg grating sensor" Opt. Laser Engineering , Vol. 31, 1999, pp.297-324

[2] G. Fanti, "Thermo-mechanical characterization of fiber Bragg grating sensors", Proc. of $V^{\circ}$ Congresso Nazionale di Misure Meccaniche e Termiche, Padua, Italy 17-19/09/2002

[3] L. D’Acquisto, R. Montanini, “On the behaviour of in-fibre Bragg grating sensors for strain measurement on plane and curved surfaces" XVII IMEKO World Congress Metrology in the 3rd Millennium June 22-27, 2003, Dubrovnik, Croatia

[4] B. Marchetti, R. Montanini, C. Rondini, P. Maggiorana, G.L. Rossi, "Definition of FBG sensor photoelastic coefficient by laser doppler vibrometery”, Fifth International Conference on Vibration Measurements by Laser Techniques: Advances and Applications, Proceedings of. SPIE Vol. 4827 (2002).

[5] L. D’Acquisto, R. Montanini, "Monitoraggio del processo di cura di compositi laminati mediante sensori in fibra ottica”, Atti VI Congresso Nazionale di Misure Meccaniche e Termiche, Desenzano del Garda (BS), Italia, 12-14 settembre 2005. 